\title{
Predicting connectivity, population size and genetic diversity of Sunda clouded leopards across Sabah, Borneo
}

\author{
Andrew J. Hearn • Samuel A. Cushman • Benoit Goossens • Joanna Ross • \\ Ewan A. Macdonald $\cdot$ Luke T. B. Hunter $\cdot$ David W. Macdonald
}

Received: 23 April 2018/Accepted: 9 November 2018/Published online: 16 January 2019

(C) The Author(s) 2019

\begin{abstract}
Context The Sunda clouded leopard is vulnerable to forest loss and fragmentation. Conservation of this species requires spatially explicit evaluations of the effects of landscape patterns on genetic diversity, population size and landscape connectivity.

Objectives We sought to develop predictions of Sunda clouded leopard population density, genetic diversity and population connectivity across the state of Sabah, Malaysian Borneo. We also wished to
\end{abstract}

A. J. Hearn $(\bowtie)$ J. Ross · E. A. Macdonald .

D. W. Macdonald

Wildlife Conservation Research Unit (WildCRU),

Department of Zoology, University of Oxford, Oxford,

UK

e-mail: Andrew.hearn@zoo.ox.ac.uk

\section{S. A. Cushman}

US Forest Service, Rocky Mountain Research Station, 2500 S Pine Knoll Dr, Flagstaff, AZ 86001, USA

B. Goossens

Danau Girang Field Centre, c/o Sabah Wildlife

Department, Wisma Muis, 88100 Kota Kinabalu, Sabah,

Malaysia

B. Goossens

Sabah Wildlife Department, Wisma Muis,

88100 Kota Kinabalu, Sabah, Malaysia

B. Goossens

Organisms and Environment Division, School of

Biosciences, Cardiff University, Sir Martin Evans

Building, Museum Avenue, Cardiff CF10 3AX, UK quantify the differences in connectivity metrics from an empirically optimized model of landscape resistance with one based on expert opinion.

Methods We investigated connectivity metrics for Sunda clouded leopards across Sabah, based on an empirically optimised, movement based model, and an expert-opinion derived model. We used simulation modelling to predict and compare the patterns and causes of differences in the local neighbourhood population density, distribution, and genetic diversity

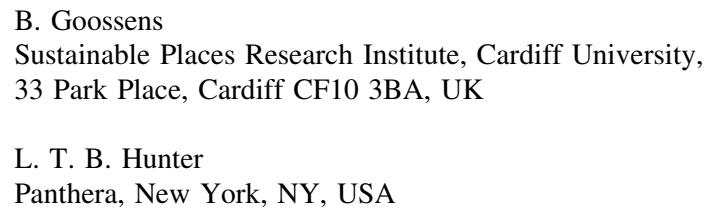


across the two different resistance maps, at two dispersal distances.

Results The empirical model produced higher estimates of population size, population density, genetic diversity and overall connectivity than the expertopinion model. The overall pattern of predicted connectivity was similar between models. Both models identified a large patch of core habitat with high predicted connectivity in Sabah's central forest region, and agreed on the location and extent of the main isolated habitat fragments.

Conclusions We identified clear relationships between landscape composition and configuration and predicted distribution, density, genetic diversity and connectivity of Sunda clouded leopard populations. Core areas are comprised of large and unfragmented forest blocks, and areas of reduced forest cover comprise barriers among patches of predicted remaining habitat.

Keywords Clouded leopard · Connectivity · UNICOR · CDPOP · Fragmentation · Habitat loss

\section{Introduction}

In the face of accelerating global habitat loss and fragmentation there is an increasing need to predict accurately how changes to landscape structure affect the population connectivity of threatened species (Spear et al. 2010; Zeller et al. 2012; Cushman et al. 2013a). Such insights can provide a foundation upon which to develop effective conservation action (Chetkiewicz et al. 2006). At its core, population connectivity is the product of the movement of individual organisms across a landscape, the surface of which varies in its resistive qualities. Such movements are shaped by the compounding influences of the composition and structure of the landscape (Zeller et al. 2013), the distribution and density of the population (Cushman 2006), and the specific dispersal traits of the species (e.g., Abrahms et al. 2017). Of these, the complex interplay between a species' dispersal characteristics and landscape features is arguably the most important factor mediating landscape resistance and subsequent population connectivity (Spear et al. 2010; Zeller et al. 2012). In most populations, however, there is substantial uncertainty about all of these parameters.

In the vast majority of applications expert-opinion has been used to parameterize resistance surfaces (Spear et al. 2010; Zeller et al. 2012). This has potentially serious limitations given that expert-opinion is of unknown quality and may often fail to reflect accurately the resistance experienced by animals when moving across the landscape (e.g., Shirk et al. 2010; Wasserman et al. 2010; Shirk et al. 2015). This is particularly true of many threatened species, for which even a basic understanding of their ecology is often lacking. A number of methods have been developed to estimate landscape resistance empirically using genetic (e.g., Cushman et al. 2006; Shirk et al. 2010; Castillo et al. 2014) and movement (e.g., BlazquezCabrera et al. 2016; Cushman et al. 2016; Zeller et al. $2017,2018)$ data. These approaches have the advantage that they are directly estimated using data from the key processes of interest. Indeed, when compared with expert-opinion or habitat suitability based measures, resistance surfaces directly estimated from movement and genetic data have shown superior performance (e.g., Shirk et al. 2010; Wasserman et al. 2010; Mateo Sánchez et al. 2014, 2015; Zeller et al. 2018). Movement and genetic data are often lacking for many threatened species, however, and are typically very costly to acquire. In the absence of such empirical data, expert opinion based estimates of landscape resistance may therefore provide a useful initial prediction of population connectivity, particularly for those species for which a basic understanding of habitat associations is available (e.g., Riordan et al. 2015; Moqanaki and Cushman 2016).

The forests of Borneo host one of the richest biological assemblages on Earth, yet the island is also a global hotspot of forest loss and degradation (Gaveau et al. 2014; Cushman et al. 2017). These anthropogenic driven changes to Borneo's forests are exemplified by the Malaysian state of Sabah, which occupies the northern part of the island. In 2010, forest accounted for $47.5 \%$ of the state's land area $\left(35,006 \mathrm{~km}^{2}\right)$, following a rapid decline from $78.6 \%$ in 1973, representing the highest deforestation rate of all the political units on Borneo during this period (Gaveau et al. 2014). Selective logging activities have been the primary driver of forest degradation throughout the state, and the subsequent conversion of these degraded forests to mono-culture plantations, chiefly 
that of oil palm (McMorrow and Talip 2001), remains the principal driver of forest loss (Gaveau et al. 2014). In 2015 oil palm plantations accounted for around $21 \%$ of land area $\left(15,442 \mathrm{~km}^{2}\right)$ in 2015 (Malaysian Palm Oil Board 2016). Understanding the impact of such changes to species of conservation concern remains a research priority.

Individual species responses to logging regimes vary, but research is increasingly showing that selectively logged Bornean forests can retain considerable levels of pre-disturbance biodiversity (e.g., Meijaard et al. 2005; Costantini et al. 2016), as well as the capacity to serve as corridors for less disturbance tolerant species moving between intact forest fragments. The establishment of industrial scale plantations of oil palm Elaeis guineensis, however, can lead to dramatic declines in species richness (e.g., Fitzherbert et al. 2008) and greatly inhibit connectivity of forest dependent species (e.g., Hearn et al. 2018). Thus, for species of conservation concern on Borneo there is an urgent need for connectivity modelling to assess impacts of landscape change to inform the development of effective conservation strategies.

The Sunda clouded leopard Neofelis diardi is the apex carnivore on the Sundaic islands of Borneo and Sumatra, where it is threatened with extinction (Hearn et al. 2015). This felid is charismatic (Macdonald et al. 2015), wide-ranging (Hearn et al. 2013), and closely associated with forest (Hearn et al. 2016, 2017), and thus serves as a potential flagship species for Bornean wildlife and a useful model with which to develop predictions of connectivity. In the first study to explore patterns of connectivity for the Sunda clouded leopard, Brodie et al. (2015) used hierarchical modelling of camera-trap data to assess and identify potential dispersal and corridor routes within a transboundary network of protected areas in Borneo. Hearn et al. (2018) analysed movement data within a path-selection framework to develop the first multi-scale, empirical connectivity predictions for a population of Sunda clouded leopards in eastern Sabah, and showed that movement is facilitated by forest canopy cover and resisted by non-forest vegetation, particularly plantation areas with low canopy closure. In the only large-scale analysis of Sunda clouded leopard connectivity, Macdonald et al. (2018) used spatially synoptic modelling, combining resistant kernel and factorial least cost path analysis (Cushman et al. 2013a, 2014), to predict patterns and changes in connectivity across the entire island of Borneo. They estimated that between 2000 and 2010 the proportion of landscape connected by dispersal had fallen by approximately $24 \%$ and the largest patch size had declined by around $30 \%$, leading to a $13 \%$ decline in clouded leopard numbers. Macdonald et al.'s (2018) analysis, however, was based on an expert-opinion derived model of Sunda clouded leopard resistance to movement, and so warrants empirical testing. In addition, conservation is conducted at the regional scale by state and provincial governments and thus effective planning of such action requires the development of connectivity predictions at these spatial scales.

In this paper we had two main objectives. First, we sought to extrapolate the Hearn et al. (2018) empirical resistance model to predict population density, genetic diversity and population connectivity for Sunda clouded leopards across the full extent of Sabah. Second, we wished to quantify the differences in predicted population density, genetic diversity and population connectivity obtained from the Hearn et al. (2018) empirically optimized and the Macdonald et al. (2018) expert-opinion resistance surfaces at the full Sabah extent. We hypothesised that $\left(\mathrm{H}_{1}\right)$ the empirical resistance model would produce higher estimates of population size, population density, genetic diversity and overall connectivity than the expert-opinion derived model, but that $\left(\mathrm{H}_{2}\right)$ the overall pattern of predicted connectivity would be the same in the two analyses, identifying the same major core areas and main areas of connectivity between them.

\section{Methods}

Study area

The Malaysian state of Sabah occupies an area of $73,631 \mathrm{~km}^{2}$ in the northernmost portion of Borneo (Fig. 1). Akin with the rest of the island, Sabah is characterised by a rugged topography, particularly in central and western areas, which give way to coastal alluvial plains.

Considerable areas of highly disturbed, regenerating forests, characterised by areas of scrub and grassland are also present in the state. A number of relatively small $\left(280-1399 \mathrm{~km}^{2}\right)$ patches of protected primary forest remain in the state, including the 


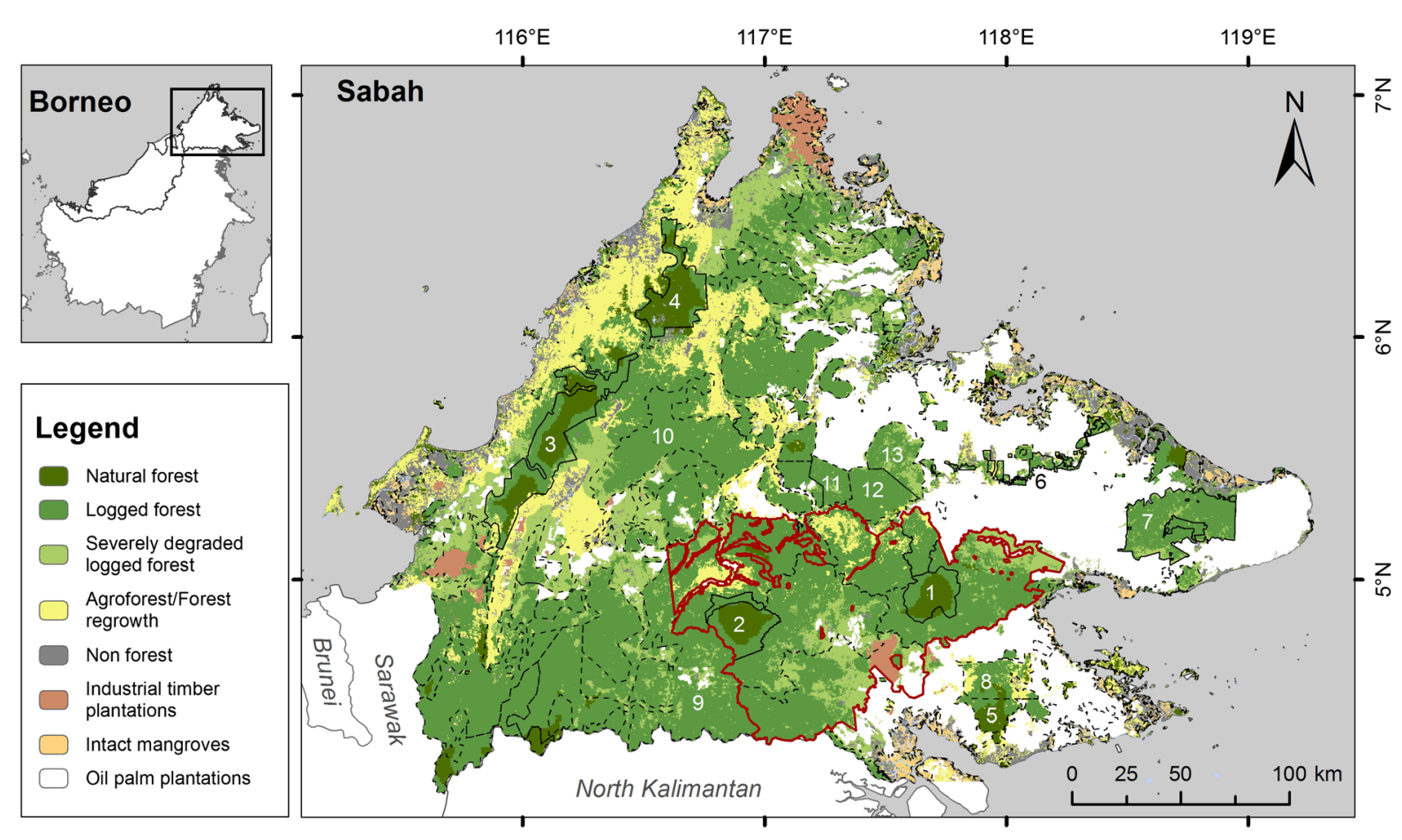

Fig. 1 Map of the Malaysian state of Sabah, northern Borneo, showing land use in 2010 (Gaveau et al. 2014). Fully protected forest areas (National Parks, Wildlife Reserves and Conservation Areas) are outlined in solid black lines and include: (1) Danum Valley and (2) Maliau Basin Conservation Areas, (3) Crocker Range, (4) Kinabalu and (5) Tawau Hills Parks, (6) Lower Kinabatangan Wildlife Sanctuary and (7) Tabin Wildlife

Danum Valley, Maliau Basin and Imbak Canyon Conservation Areas, and the Crocker Range, Kinabalu and Tawau Hills Parks (Fig. 1), but the vast majority of remaining forest has undergone one or more rounds of selective logging (Reynolds et al. 2011). The stateowned Permanent Forest Reserve, which includes State Parks, Wildlife Reserves as well as commercial Forest Reserves, now accounts for the majority of remaining forest (Reynolds et al. 2011). The rugged areas along the Crocker and Trusmadi mountain ranges retain large areas of forest in the western and southwestern parts of the state, and sizeable areas in the central areas of the state remain forested, most notably the $10,000 \mathrm{~km}^{2}$ Yayasan Sabah Forest Management area (YSFMA; Reynolds et al. 2011). Deforestation rates have been significantly higher in the eastern side of Sabah, however, and a number of protected forest areas, including the Tabin Wildlife Reserve, Lower Kinabatangan Wildlife Sanctuary and
Reserve. Commercial Forest Reserves are outlined in dashed black lines; key areas include (8) Ulu Kalumpang, (9) Sapulut, (10) Trus Madi, (11) Tankulap-Piningah, (12) Deramakot and (13) Segaliud Lokan Forest Reserves. The Yayasan Sabah Forest Management Area is outlined in dark red. Polygons represent the state owned, Permanent Forest Reserve system. (Color figure online)

Tawau Hills Park, are no longer contiguous with the core forest regions.

\section{Development of resistance layers}

We investigated connectivity metrics for Sunda clouded leopards across the full extent of Sabah, based on two resistant surfaces, each developed using different methodological approaches. The two resistance models consisted of Hearn et al's (2018) empirically optimised, movement based model, and Macdonald et al.'s (2018) expert-opinion derived model, hereafter referred to as the Empirical model and Expert model, respectively. The Empirical model resistance layer was developed by Hearn et al. (2018) using conditional logistic regression in a path-selection context (e.g., Cushman et al. 2010; Cushman and Lewis 2010), applied to movement data derived from GPS tagged Sunda clouded leopards residing in an approximately $4000 \mathrm{~km}^{2}$ study extent in eastern 
Sabah, the Lower Kinabatangan Wildlife Sanctuary and surrounding oil palm matrix. Hearn et al. (2018) used a multiscale approach and evaluated three scales of spatial shift to investigate relationships between clouded leopard movement paths and a range of landscape variables. To enable extrapolation of the local-scale model to the entire state of Sabah, we recomputed the path selection function based on reclassified land cover data that was available at Sabah scale. We assumed that all kinds of upland forest were equivalent, reclassifying two classes of montane forest to the same value as lowland tropical forest which was present in the Hearn et al. (2018) study area.

The expert model was developed by Macdonald et al. (2018) who conducted a survey of the leading experts on Sunda clouded leopard ecology to obtain estimates of resistance values to be assigned to different land cover types. The land cover classes were derived from those developed in a $250 \mathrm{~m}$ resolution 2010 land cover map of insular Southeast Asia, by Miettinen et al. (2012). Lowland forest and lower montane forest were ranked as the highest quality habitat with mean scores of 4.50 and 4.25 out of 5, respectively, and urban, water and large-scale plantation were given the lowest quality scores of 1.0, 1.05 and 1.11, respectively. Lowland Open and Montane Open were also given very low-quality scores. These habitat suitability index scores were translated into relative resistances by inverting and scaling from a minimum of 1 to a maximum of 100 , and subsequently applied to the Miettinen et al. (2012) map to produce a resistance surface, within the Sabah extent.

\section{Source points for connectivity modelling}

For each of the two resistance layers we developed a set of source points for use in connectivity modelling. The resistance layers describe the local cost of moving through any given pixel which is the foundation for connectivity modelling; however, resistance surfaces themselves are insufficient indicators of connectivity (Cushman et al. 2009). Connectivity is a function of the resistance surface and the density, distribution and dispersal ability of the dispersing population (Cushman et al. 2010). Thus, source points that reflect a realistic distribution and density of the population are critical to reliable predictions of connectivity
(Cushman et al. 2014). We seeded each of the two resistance layers with source points using the method described in Macdonald et al. (2018), in which clouded leopard habitat suitability is considered to be directly proportional to the inverse of resistance to movement. Specifically, we generated a raster of identical pixel size and extent as the two resistance layers, but with values randomly varying between 0 and 1 . We then multiplied this uniform random map with each of the two resistance layers, and selected all pixels with value less than a constant chosen to produce a set of 4540 points for the Empirical model resistance layer, which also produced a set of 3811 points for the Expert resistance layer, since it had higher overall resistance across Sabah and thus lower average suitability for clouded leopard occurrence. The true clouded leopard population size in Sabah is likely $1 / 4$ of that of our source point population (Hearn et al. 2017). We chose to use a higher density of source points to provide more spatial precision in the estimates of connectivity, given spatial uncertainty in the actual locations of clouded leopard home ranges and the fact that they are mobile animals and may utilize multiple locations in their lifetimes (e.g., Moqanaki and Cushman 2016).

\section{Resistant Kernel connectivity modelling}

We used the least-cost resistant kernel approach (Compton et al. 2007; Cushman et al. 2010) implemented in UNICOR v2.0 (Landguth et al. 2012) to predict the extent of the landscape connected by dispersal across a 250,000 cost unit kernel width. This kernel width was chosen since it is approximately the upper bound of the expected dispersal ability of clouded leopards (Macdonald et al. 2018). The implementation of the cumulative resistant kernel used in this paper works by computing the costdistance kernel from each source location across the resistance map and summing all such kernels to create a cumulative resistant kernel surface that reflects the incidence function of relative frequency of movement of the species through each location. Thus, the model calculates the expected relative density of each species in each pixel around the source, given the dispersal ability of the species, the nature of the dispersal function, and the resistance of the landscape (Compton et al. 2007; Cushman et al. 2010). The resistant kernel method of modelling landscape provides a 
comprehensive assessment of connectivity from the source locations to all locations (i.e., many to all) and is computationally efficient, allowing implementation at broad scales and across multiple scenarios (e.g., Cushman et al. 2012a, 2013a).

We compared the predicted connectivity obtained from the Empirical and Expert derived resistance surfaces in several ways. First, we visually interpreted the patterns of high and low resistance in each layer, noting the major differences among them. Second, we visually interpreted the patterns of cumulative kernel connectivity value in each layer, noting the major differences in predicted movement rates across the full extent of Sabah. Third, we computed FRAGSTATS (McGarigal et al. 2012) metrics on the mosaic of patches predicted to be connected by dispersal in the cumulative kernel results for each resistance surface, across a range of connectivity thresholds (e.g., Wasserman et al. 2012). We chose two metrics to compute, the percentage of the landscape (PLAND) and the correlation length (GYRATE_AM) predicted to be connected by dispersal at a given connectivity threshold value. The percentage of the landscape is the most basic metric of landscape composition, yet provides a useful quantification of the area predicted to be connected by dispersal. The correlation length measures the distance an organism can travel when placed at a random location in connected habitat and assigned to move in a random direction before reaching the edge of connected habitat (McGarigal et al. 2012), and has been shown to be a strong predictor of functional connectivity (Cushman et al. 2012b). We chose connectivity thresholds at a range of cumulative resistant kernel values, including: 0, 10, $20,40,80,160,320$ and 640, which span the range from including all areas with any level of predicted connectivity among them (0) to only those areas with exceptionally high predicted rates of clouded leopard incidence and movement (640). Finally, we computed the intersection of the cumulative resistant kernel maps for the Empirical and Expert resistance models across a range of kernel density thresholds (Cushman et al. 2013b). We calculated the extent of each of the three intersection components (connected in Empirical only, Expert only, and connected in both.
Predicted population size and genetic diversity

We used simulation modelling (e.g. Shirk et al. 2012; Wasserman et al. 2012) with an individual-based, spatially explicit population dynamics and genetics program (CDPOP version 1.0; Landguth and Cushman 2010) to predict and compare the patterns and causes of differences in the local neighbourhood population density, distribution, and genetic diversity across the two different resistance maps, at two dispersal distances. CDPOP simulates the birth, death, mating and dispersal of individuals in heterogeneous landscapes as probabilistic functions of the cost of movement through them. For each of the two landscape resistance maps, we used the source cells used in the resistant kernel analysis as locations of simulated individual clouded leopards. We used standard simulation parameters widely used in landscape genetics simulation modelling (e.g., Cushman and Landguth 2010) and stipulated the population to have 30 loci, with 10 alleles per locus, initially randomly assigned among individuals, and a mutation rate of 0.0005 . We used an inverse square mating and dispersal probability function, with maximum dispersal cost-weighted distances of $125,000 \mathrm{~m}$ and $250,000 \mathrm{~m}$, which reflect the estimated upper and lower range of expected clouded leopard dispersal ability (Macdonald et al. 2018). Reproduction was sexual with non-overlapping generations, and the number of offspring was based on a Poisson probability draw, with mean of 2 . We ran 10 Monte Carlo runs in CDPOP for each of the two landscape resistance maps to assess stochastic variability. We simulated gene flow for 200 non-overlapping generations. Past studies have shown that this is sufficient time to ensure spatial genetic equilibrium (Landguth et al. 2010a, b). We extracted several global measures of population genetic structure for the full study area at generation 200, including total population size, number of alleles in the population, and observed and expected heterozygosity (Macdonald et al. 2018). We analysed the differences in these global measures of genetic structure between the two dispersal abilities using standard single factor analysis of variance (ANOVA) implemented in the aov function of BASE package of $\mathrm{R}$. 


\section{Results}

Landscape resistance and resistant kernel connectivity models

There were striking differences between the Empirical and Expert resistance layers in predicted resistance to clouded leopard movement across the full extent of Sabah (Fig. 2-top row). Both maps predict low resistance (dark blue) in areas of primary and selectively logged forest, and both predict high resistance (red-yellow) in areas of non-forest, which, in the eastern half of the state, are characterised primarily by oil palm plantations. The main difference between the

\section{Expert model}
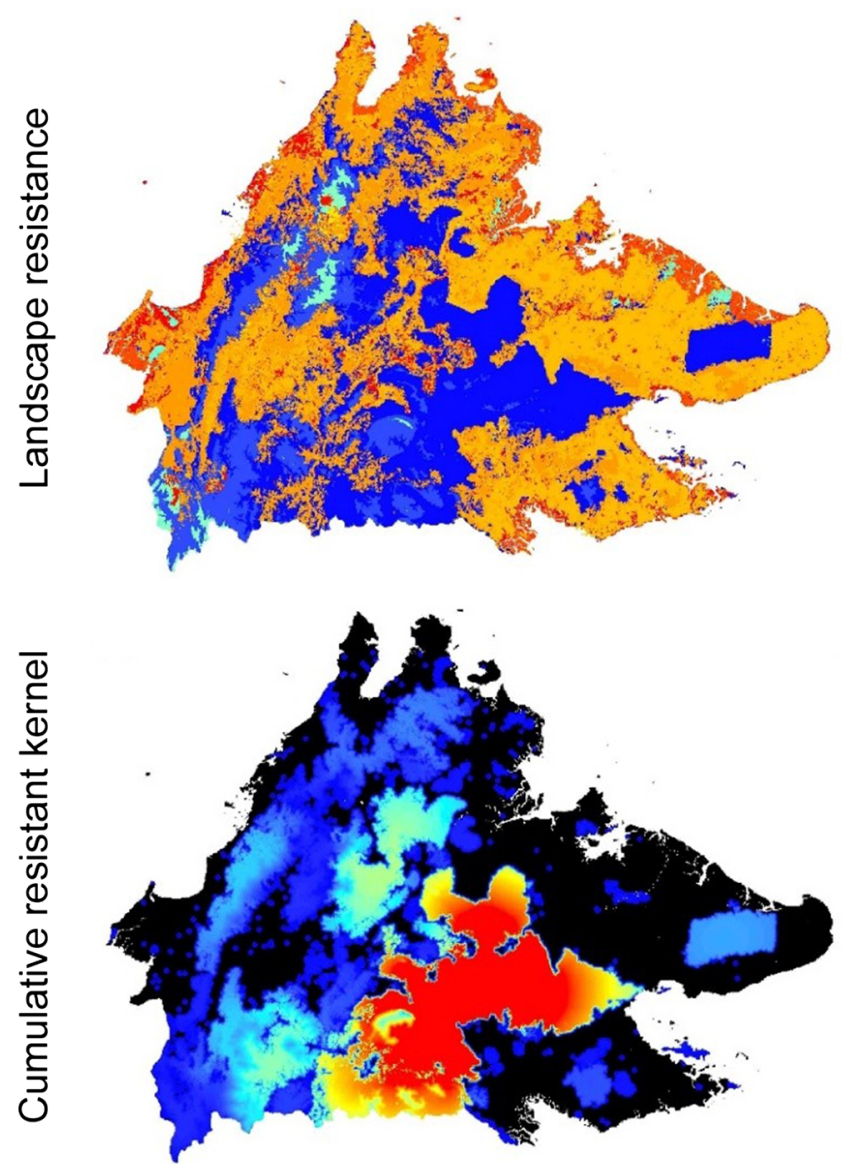

Fig. 2 Landscape resistance (top row) and cumulative resistant kernel (bottom row) maps for Sunda clouded leopard movement applied to the full extent of the State of Sabah, Malaysia. Landscape resistance model based on multi-scale optimization of a path-selection function; Resistance ranges from low (1) in maps is related to how they treat areas, particularly in the state's western half, that are classified by Miettinen et al. (2012) as Plantation/Regrowth and Lowland Mosaic, and by Gaveau et al. (2014) as Agroforest/ Forest regrowth. The Expert model predicted these areas to be relatively high resistance, while the Empirical model predicted these areas to be relatively low resistance (mid blue). Some areas classified as Severely degraded and logged forest by Gaveau et al. (2014), but as Plantation/Regrowth by Miettinen et al. (2012), such as parts of south eastern Tabin Wildlife Reserve, Ulu Kalumpang Forest Reserve (contiguous with Tawau Hills Park) and the Bukit Pithon Forest Reserve (north east of the YSFMA) were predicted as

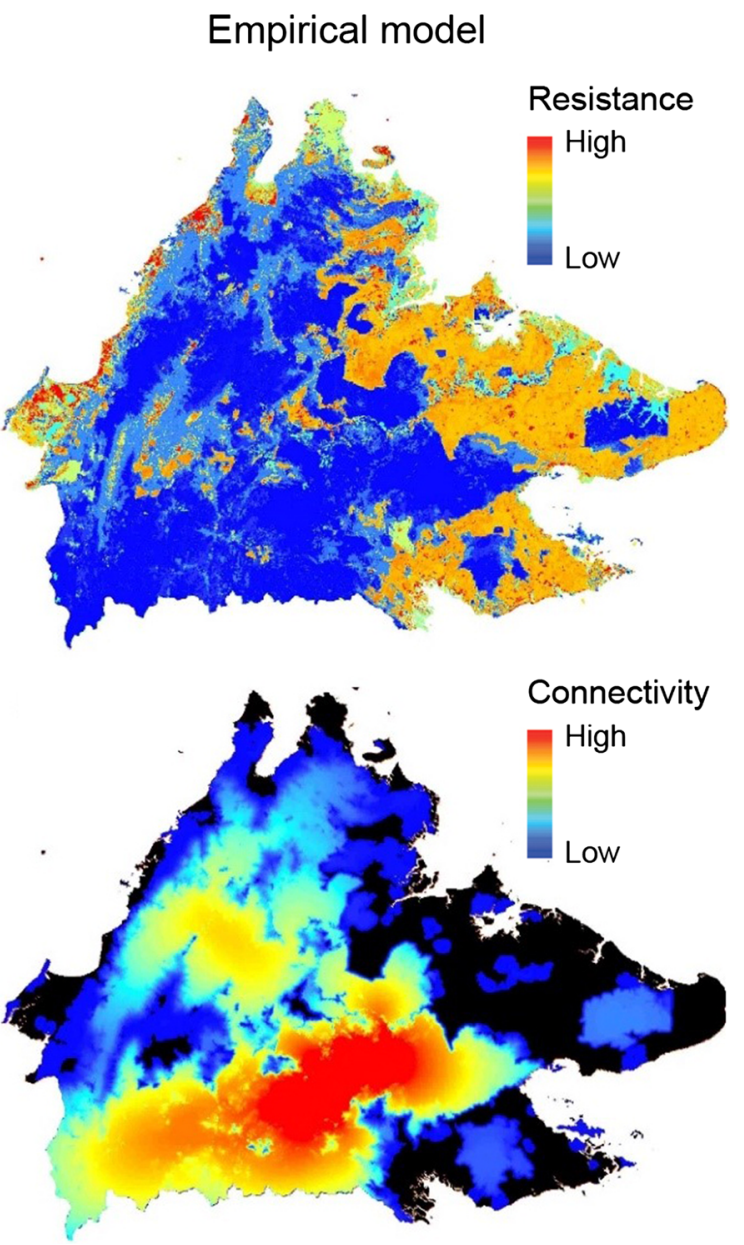

dark blue to high (100) in red; Cumulative resistant kernels developed using a 250,000 cost unit dispersal threshold; Red areas are predicted to have high density/frequency of utilization, blue areas low, and black areas are predicted to not be utilized by clouded leopards. (Color figure online) 
relatively low resistance in the Empirical map, but as relatively high (yellow-orange) in the Expert map.

The cumulative resistant kernel prediction of connectivity across Sabah differed substantially between the two resistance models (Fig. 2, bottom row). Both cumulative resistant kernel maps showed a major core area of connectivity, which encompasses the YSFMA and contiguous commercial Forest Reserves of Deramakot, Tankulap-Piningah and Segaliud Lokan, to the north, and Sapulut to the southwest. Both approaches predicted losses of functional connectivity between the YSFMA and the Lower Kinabatangan Wildlife Sanctuary, Tabin Wildlife Reserve and Tawau Hills Park. The two models' main differences were in the western half of the State, where the Expert resistance surface predicted much less connectivity than the Empirical resistance surface. This is a result of the differing resistance assigned to areas classified as Plantation Regrowth and Lowland Mosaic by Miettinen et al. (2012), and as primarily Agroforest/Forest regrowth Plantation Regrowth by Gaveau et al. (2014), as noted above. Despite these differences, both models predicted that these western and northern regions, which include the regionally important Crocker Range and Kinabalu Parks, remained functionally connected to the core areas of connectivity in and around the YSFMA and adjacent commercial Forest Reserves.

We computed FRAGSTATS metrics on the mosaic of patches predicted to be connected by dispersal in the cumulative resistant kernel results for the two resistance surfaces, across a range of connectivity thresholds. The percentage of Sabah predicted to be connected by dispersal across cumulative kernel density thresholds was substantially different between the two resistance layers (Fig. 3a). At all dispersal thresholds, cumulative resistant kernel surface obtained from the Empirical model had higher extensiveness than that obtained from the Expert model. The relative difference in the percentage of Sabah connected by dispersal increased as the connectivity threshold increased. At the most liberal threshold (cumulative kernel value greater than 0) the Empirical model cumulative resistant kernel surface had a $16 \%$ greater area than the Expert model resistant kernel surface. This difference increased at the higher levels of cumulative kernel value, reaching a difference of $20 \%$ at cumulative kernel values greater than 320 (Fig. 3a). Both maps had low extents predicted to be connected at the very highest connectivity values (less than $10 \%$ at cumulative kernel values $>640$ ).

Correlation length of connected habitat was similar between the Expert and Empirical models for all areas connected with cumulative kernel value $>0$ (Fig. 3b). There was a clear threshold at cumulative resistant kernel value of approximately 20, above which the two connectivity surfaces departed in correlation length, with the Empirical kernel surface remaining highly connected while the correlation length of the Expert surface declined dramatically (decrease of $29.60 \mathrm{~km}$ correlation length, $37 \%$ less than the correlation length of the Empirical model at a connectivity threshold of $>40$ cumulative resistant kernel value). This relative difference in correlation length of connected habitat remained the same up to cumulative resistant kernel threshold of $>320$, and then declined substantially at the highest connectivity threshold value ( $>640)$.

\section{Intersection analysis}

We computed the intersection of the cumulative resistant kernel maps for the Empirical and Expert resistance maps, across a range of kernel density thresholds (Fig. 4). We calculated the extent of each of the three intersection components [connected in the Empirical map only, connected in the Expert map only, and connected in both maps (Fig. 5)]. At low cumulative kernel thresholds, the vast majority of the area predicted to be connected in either map is connected in both maps (Fig. 4a, 5). The proportion of intersection declines as the cumulative resistant kernel threshold increases, such that at high levels of connectivity there is much less overlap between the areas predicted to be connected in the two approaches (Fig. 4e-g). At the very highest level of connectivity value there is much less total area predicted to be connected in either analysis, and only at this very high level of connectivity value does the Expert analysis predict connectivity in areas not also predicted to be connected in the Empirical analysis.

Predicted population size and genetic diversity

We used the program CDPOP to predict and compare differences in population size, distribution, and genetic diversity across the two different resistance maps. There was considerable local variation in 
Fig. 3 a Percentage of the landscape predicted to be connected and $\mathbf{b}$ Correlation length of connected habitat across a range of cumulative resistant kernel surface thresholds, for the Hearn et al. (2018) Empirical model and Macdonald et al. (2018) Expert-opinion model
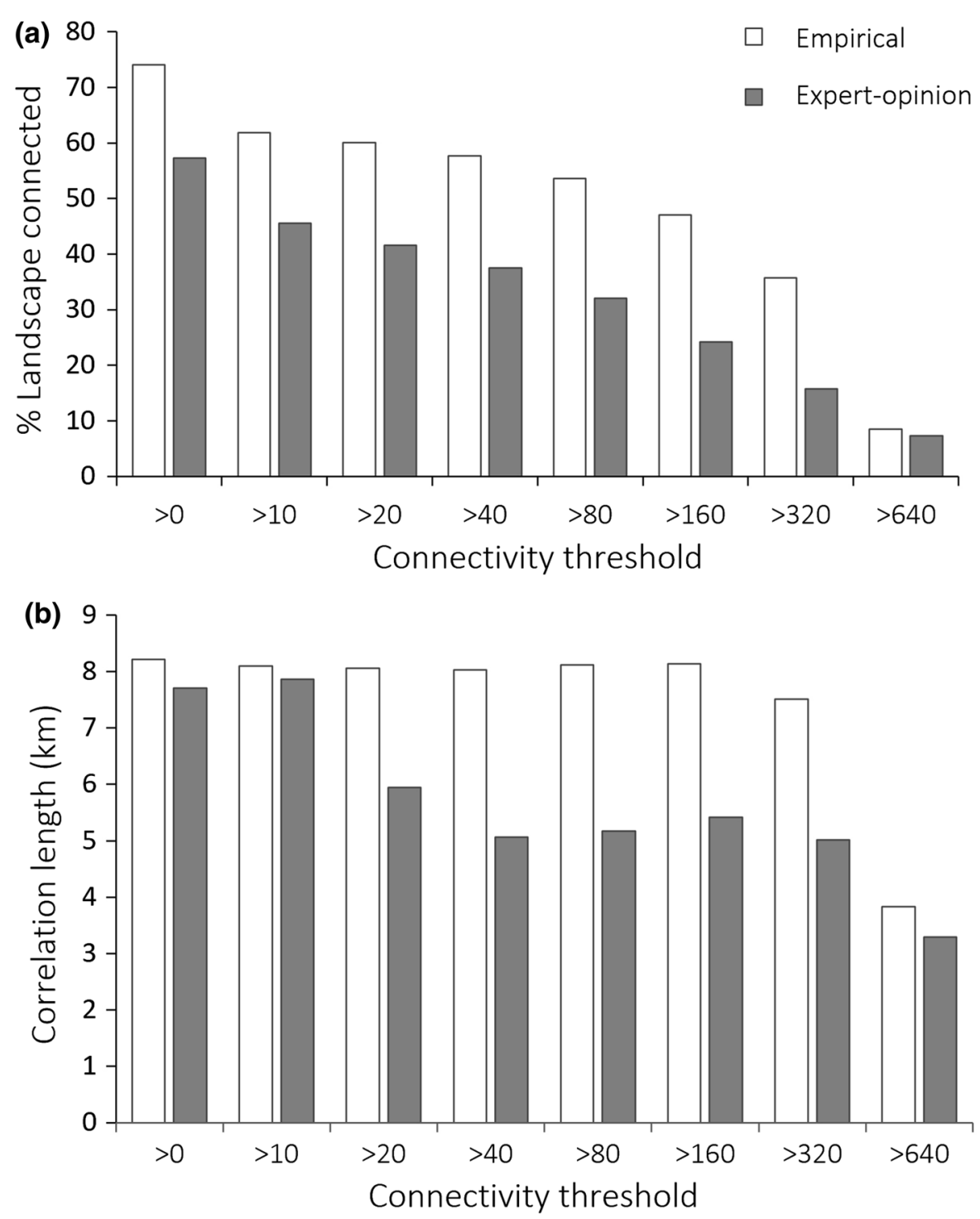

simulated local neighbourhood population density of clouded leopards across Sabah among the four CDPOP scenarios (Fig. 6). The general pattern was for broader distribution and larger populations in the Empirical resistance map simulations than the Expert resistance map simulations, and in the long versus short dispersal ability simulations. We found that the effect of resistance layer on simulated population size across the full extent of Sabah was statistically significant, whereas the effect of dispersal ability was not (Table 1; Fig. 7a). All four simulations predicted that population density was highest within a core central area which encompassed the YSFMA and adjacent Deramakot, Tankulap-Piningah and
Segaliud Lokan Forest Reserves. The Empirical model scenarios also predicted relatively high population densities in the highland areas of the Crocker and Trus Madi mountain ranges and along the border with Kalimantan and Sarawak, in south-western Sabah, but these areas were predicted as only moderate density in the Expert model scenarios. All four simulations show populations persisting in the relatively isolated forest patches of the Crocker Range and Kinabalu Parks, and Tabin Wildlife Reserve. In contrast, only the simulations on the Empirical resistance maps show the population persisting in Tawau Hills Park, and Sunda clouded leopards were predicted to persist in the 

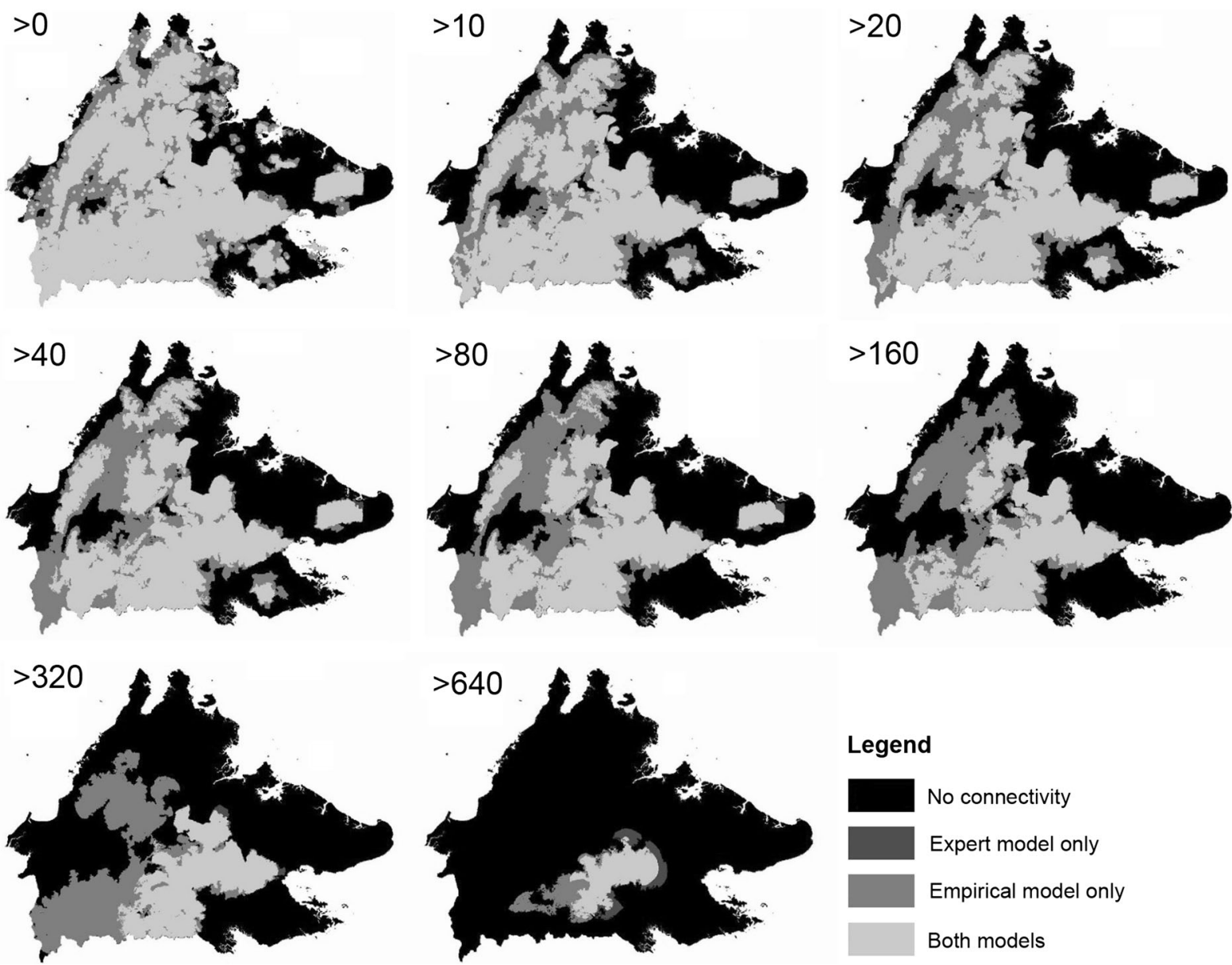

Legend

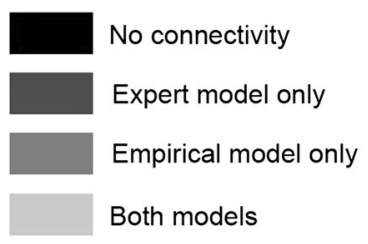

Fig. 4 Intersections between the cumulative resistant kernel surfaces produced on the Expert model (Macdonald et al. 2018) map only, Empirical model (Hearn et al. 2018) map only, and

Lower Kinabatangan Wildlife Sanctuary only in the Empirical simulation with the high dispersal ability.

There were significant differences in the number of alleles in the Sabah-wide clouded leopard population among resistance maps, but not dispersal abilities or their interaction (Table 1, Fig. 7b), with the simulations on the Empirical resistance map producing significantly higher allelic richness than simulations on the Expert resistance map. There were significant differences in the heterozygosity of the Sabah-wide clouded leopard population among resistance maps and dispersal abilities, but not their interactions (Table 1, Fig. 7c). Specifically, heterozygosity was significantly higher in the CDPOP simulations on the Empirical resistance map than on the Expert resistance map, and significantly higher in simulations with the both maps, across eight different cumulative kernel connectivity values (shown in top left of each map)

long dispersal distance than the short dispersal distance.

\section{Discussion}

Our goals in this study were to predict the local neighbourhood population density, genetic diversity and map patterns of population connectivity for Sunda clouded leopards across Sabah and compare the differences in predictions obtained from expert-opinion and empirically derived resistance maps. Consistent with our first hypothesis, we found that the Empirical resistance model produced higher estimates of population size, population density, genetic diversity and overall connectivity than the Expert model. 


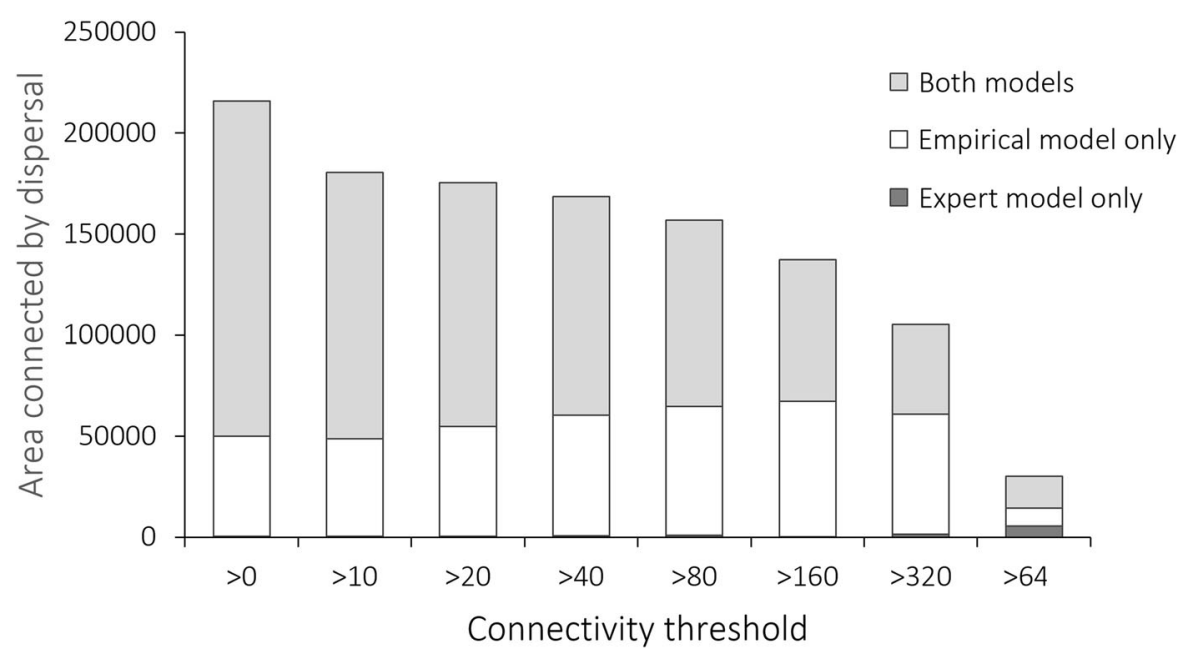

Fig. 5 Intersection analysis of areas predicted to be connected by dispersal on the Empirical model (Hearn et al. 2018) map only, Expert model (Macdonald et al. 2018) map only, and both maps, across a range of cumulative resistant kernel surface thresholds: $(>0,>10,>20,>40,>80,>160,>320,>640)$

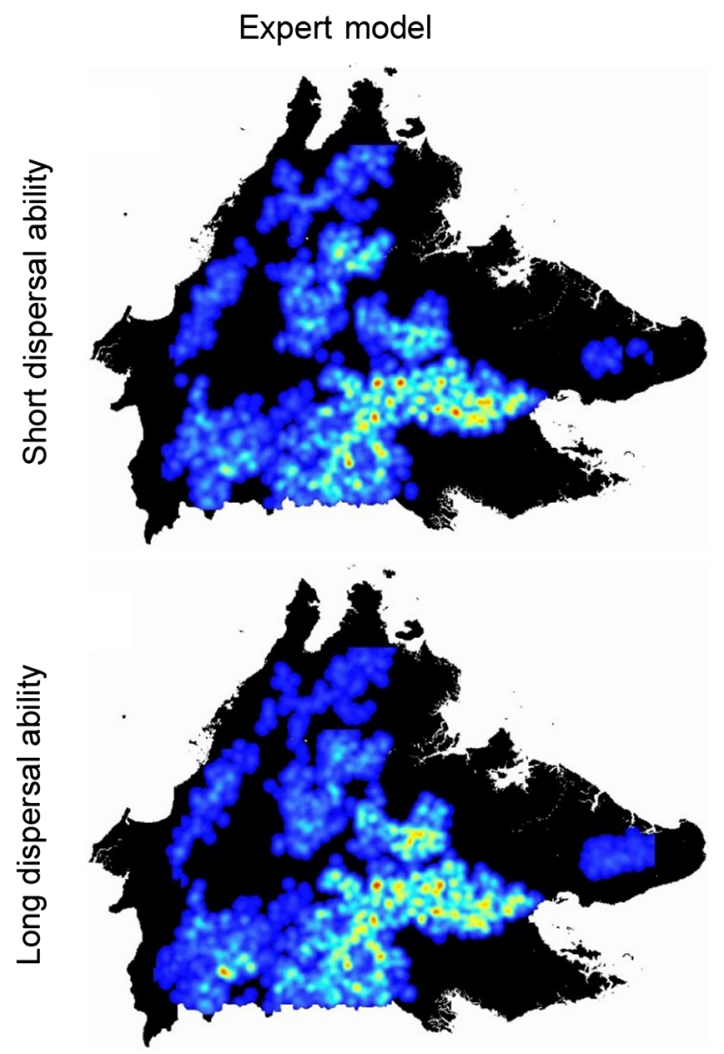

Fig. 6 Mean predicted local neighbourhood density of clouded leopards across Sabah under four simulation scenarios: First column: Macdonald et al. (2018) Expert-opinion model; second column: Hearn et al. (2018) Empirical model; top row: Short

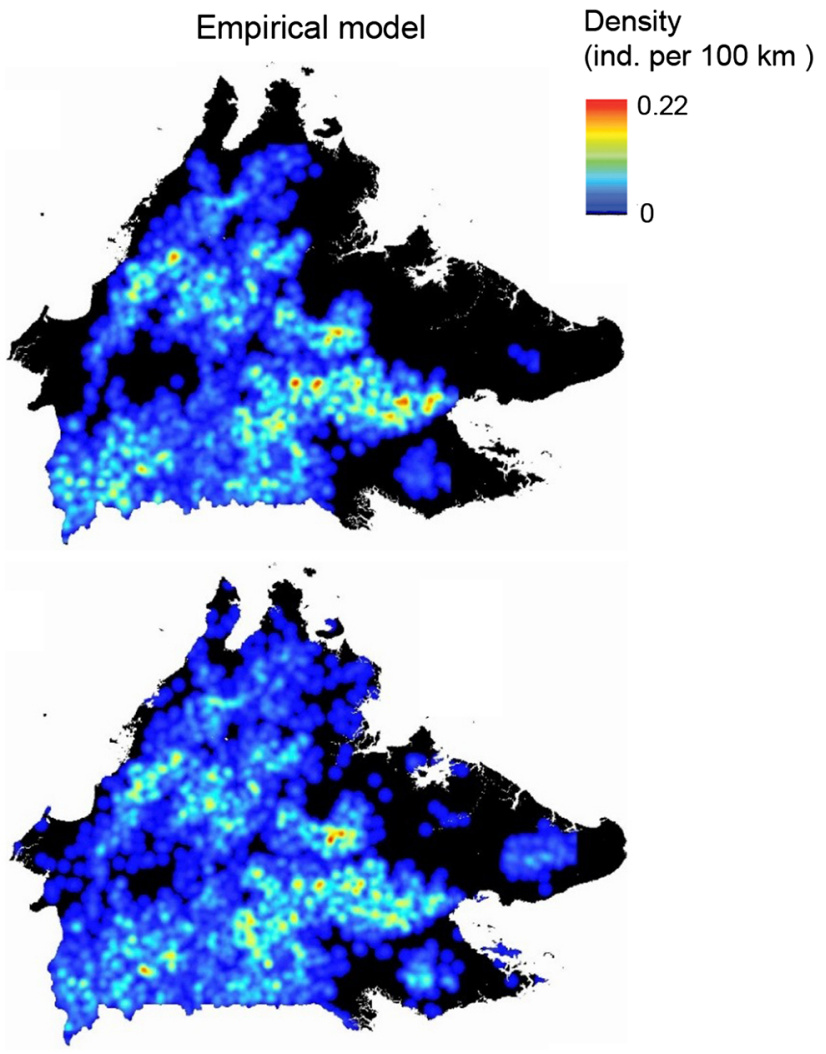

dispersal ability (250,000 cost unit dispersal threshold); bottom row: Long dispersal ability (125,000 cost unit dispersal threshold) 
Table 1 Results of Two-way Analysis of Variance of differences between simulated populations, alleles, and heterozygosity as function of dispersal ability and the resistance map used

\begin{tabular}{llll}
\hline Effect & \multicolumn{3}{l}{ Analysis of variance P-values } \\
\cline { 2 - 4 } & Population size & Alleles & Heterozygosity \\
\hline Dispersal ability & 0.533 & 0.191 & 0.021 \\
Resistance map & 0.010 & 0.025 & 0.035 \\
Interaction: dispersal ability—resistance map & 0.323 & 0.369 & 0.730 \\
\hline
\end{tabular}

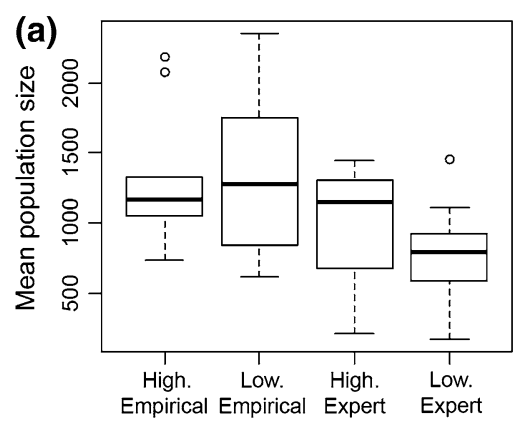

Fig. 7 Boxplots of simulated mean a Sunda clouded population size across Sabah, b number of alleles in the Sabah-wide population of Sunda clouded leopards, $\mathbf{c}$ heterozygosity for the Sabah-wide population of Sunda clouded leopards, for the Empirical model (Hearn et al. 2018) and Expert-opinion model

The Expert based resistance layer produced by Macdonald et al. (2018) was based on relative suitability estimates for different landcover types, and several landcover types that are common in western Sabah were absent in the Kinabatangan study area; thus the two resistance layers and connectivity predictions obtained from them may differ in areas where these cover types are common. In addition, the Expert resistance layer was based solely on the expert opinion weights given to land cover classes, while the Empirical model also included additional variables related to canopy cover. Thus, the Empirical model predicted relatively low resistance in some areas with moderately high canopy cover, even if they were in cover types given relatively high resistance in the Expert model. For example, the Expert model predicted much higher resistance in a large region of northern and western Sabah, specifically in areas classified as Plantation/Regrowth and Lowland Mosaic by Miettinen et al. (2012) and as Agroforest/ Forest regrowth by Gaveau et al. (2014). The differences in inferred resistance value in these areas

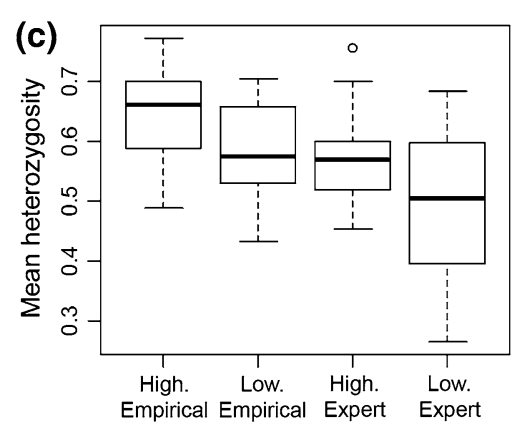

(Macdonald et al. 2018) resistance maps, at 250,000 cost units (High) and 125,000 cost units (Low) dispersal abilities. Error bars represent $95 \%$ Confidence intervals and boxes represent interquartile ranges $(25-75 \%)$

propagated to large differences in predicted population density, genetic diversity and population connectivity, with the Empirical model predicting higher density, genetic diversity and connectivity in these parts of Sabah. It is impossible to determine based on existing data which resistance parameterization is more accurate. Further work will be required to document patterns of density, genetic diversity and movement and/or genetic differentiation as a function of landscape features in this region of Sabah where the predictions described here differ.

Our second hypothesis proposed that, despite their differences, the overall pattern of predicted connectivity would be similar between the two models, identifying the same major core areas and main areas of connectivity between them. Additionally, we expected that there would be higher similarity between the connectivity predictions than between the resistance surfaces themselves, since connectivity is a spatially contagious spread process that smooths local differences in resistance. Our results largely support this hypothesis. Both analyses identified a large patch 
of core habitat with high predicted cumulative resistant kernel connectivity value in the YSFMA and contiguous commercial Forest Reserves. Importantly, however, the analysis based on the Empirical model predicted this core area to extend west along the border with Kalimantan and Sarawak, in south-western Sabah, and also westward, encompassing and linking the mountainous areas of the Trus Madi Forest Reserve and Crocker Range and Kinabalu Parks. In contrast, the Expert based resistance model predicted these areas to have low connectivity and low rates of predicted movement of clouded leopards through them. So while the models agreed in terms of the location of the most important core area they differed substantially in the extent of that core population.

Despite their differences, both models agreed on the location and extent of the main isolated fragments of internally connected habitat. Namely, they each identified the Lower Kinabatangan Wildlife Sanctuary, Tabin Wildlife Reserve and Tawau Hills Park as patches of habitat predicted to have extant clouded leopard populations, but predicted to be isolated from other populations. Efforts should be made to explore mechanisms to increase connectivity between these areas and the main central forest, such as establishment of riparian corridors, and identification and/or creation of High Conservation Value forest areas within plantations landscapes.

\section{Scope and limitations}

To apply the Hearn et al. (2018) resistance model to the full extent of Sabah we assumed that all kinds of upland forest were equivalent, reclassifying two classes of montane forest to the same value as lowland tropical forest (which was present in the Hearn et al. (2018)) study area. Whilst there are no empirical movement data to test these assumptions (e.g., the movement data used in the empirical model was from a part of Sabah where these upland forest types are absent), occurrence data from camera trap studies support the notion that clouded leopards are found in these forested uplands at relatively high densities (Hearn et al. 2017). However, in the absence of such empirical movement data, and since the movement model was based on data from a small number of individuals, we should view this model as preliminary.

Further research should strive to improve ecological understanding of how landscape conditions affect clouded leopard occurrence and dispersal. The best way to resolve the differences between the empirical and expert predictions would be to obtain additional data on clouded leopard occurrence patterns, genetic structure and movement. Broad-scale monitoring of occurrence patterns would enable empirical estimates of distribution and abundance that could be used to validate the two predictions presented here. In addition, further work with empirical modelling of resistance based on telemetry in other parts of Sabah, ideally targeting the range of different age/sex classes, and focusing on habitat types not included in the current model, would help to generalize the empirical model across the broader extent, enabling more robust comparison of the Empirical vs. Expert-opinion models. This kind of meta-replicated study to generalise ecological relationships across broad scales has been highly useful for other carnivore species (e.g., Short Bull et al. 2011; Shirk et al. 2014), and has been identified as one of the keys to reliable inferences about pattern-process relationships at the landscape level (McGarigal and Cushman 2002).

Future research should also focus on how different landscape management approaches affect the conservation of this felid. In this regard it would be valuable to develop a scenario-based analysis that includes likely development and conservation actions for the region and use the modelling approach presented here to quantitatively measure their relative impacts on population size, connectivity and genetic diversity. We hope that future work will help to close the gap in understanding through a combination of occurrence, genetics and movement modelling for this species across its range.

Landscape connectivity predictions are the combined result of three main things: (1) the density and distribution of the source population, (2) landscape resistance and (3) dispersal ability. Our goal was to evaluate how the two different resistance maps, from expert and empirical analysis, differ in their implications for connectivity. In our analysis the two resistance maps affect both (1) density and distribution of source points and (2) landscape resistance. It would be good to isolate the effects of differential resistance by holding density and distribution of source points constant. However, source points must be located to represent the density and distribution of the subject population. The two resistance maps suggest quite different things about clouded leopard habitat and 
movement selection, such that it would be incorrect to use source points predicted by one to analyse connectivity of the other. The locations of the points needs to be proportional to predicted suitability, and the suitability is different in the expert and empirical analysis so the points are different and must be different between the two analyses. As a result we cannot separate source points and landscape resistance, and thus our analysis is of the differences in the predicted connectivity and population size implied by the two maps in full, which includes both effects of different source points and effects of different landscape resistance. Future work should assess the independent and interactive effects of source points and resistance on connectivity. That is a more theoretical question than what this paper explored and would best be addressed in a simulation study in which neutral models (e.g., Cushman et al. 2013c; Shirk et al. 2018) are used to generate landscapes of different patterns of resistance and different densities and distributions of points, and then landscape connectivity and landscape genetic analyses carried out on combinations of resistance and source points, enabling the separation of their effects.

Acknowledgements We thank Sabah Wildlife Department, Sabah Forestry Department and the Sabah Biodiversity Centre for permission to conduct research. This research was funded by the Robertson Foundation, Sime Darby Foundation, RecanatiKaplan Foundation, Clouded Leopard Project, Dr Holly Reed Wildlife Conservation Fund, Point Defiance Zoo and Aquarium, Houston Zoo, and Panthera.

Open Access This article is distributed under the terms of the Creative Commons Attribution 4.0 International License (http:// creativecommons.org/licenses/by/4.0/), which permits unrestricted use, distribution, and reproduction in any medium, provided you give appropriate credit to the original author(s) and the source, provide a link to the Creative Commons license, and indicate if changes were made.

Data availability The datasets generated during and/or analysed during the current study are not publicly available due to the fact that they contain location data regarding a threatened species in a protected area, but are available from the corresponding author on reasonable request.

\section{References}

Abrahms B, Sawyer SC, Jordan NR, McNutt JW, Wilson AM, Brashares JS (2017) Does wildlife resource selection accurately inform corridor conservation? J Appl Ecol 54:412-422

Blazquez-Cabrera S, Gastón A, Beier P, Garrote G, Simón MÁ, Saura S (2016) Influence of separating home range and dispersal movements on characterizing corridors and effective distances. Landscape Ecol 31:2355-2366

Brodie JF, Giordano AJ, Dickson B, Hebblewhite M, Bernard H, Mohd-Azlan J, Anderson J, Ambu L (2015) Evaluating multispecies landscape connectivity in a threatened tropical mammal community. Conserv Biol 29(1):122-132

Castillo JA, Epps CW, Davis AR, Cushman SA (2014) Landscape effects on gene flow for a climate-sensitive montane species, the American pika. Mol Ecol 23(4):843-856

Chetkiewicz C-LB, St. Clair CC, Boyce MS (2006) Corridors for conservation: integrating pattern and process. Annu Rev Ecol Evol Syst 37:317-342

Compton BW, McGarigal K, Cushman SA, Gamble LR (2007) A resistant-kernel model of connectivity for amphibians that breed in vernal pools. Conserv Biol 21(3):788-799

Costantini D, Edwards DP, Simons MJ (2016) Life after logging in tropical forests of Borneo: a meta-analysis. Biol Cons 196:182-188

Cushman SA (2006) Effects of habitat loss and fragmentation on amphibians: a review and prospectus. Biol Conserv 128(2):231-240

Cushman SA, Landguth EL (2010) Spurious correlations and inference in landscape genetics. Mol Ecol 19:3592-3602

Cushman SA, Lewis JS (2010) Movement behavior explains genetic differentiation in American black bears. Landscape Ecol 25(10):1613-1625

Cushman SA, McKelvey KS, Hayden J, Schwartz MK (2006) Gene flow in complex landscapes: testing multiple hypotheses with causal modeling. Am Nat 168(4):486-499

Cushman SA, McKelvey KS, Schwartz MK (2009) Use of empirically derived source-destination models to map regional conservation corridors. Conserv Biol 23(2):368-376

Cushman SA, Chase M, Griffin C (2010) Mapping landscape resistance to identify corridors and barriers for elephant movement in southern Africa. In: Cushman SA, Huettmann F (eds) Spatial complexity, informatics, and wildlife conservation. Springer, Tokyo, pp 349-367

Cushman SA, Landguth EL, Flather CH (2012a) Evaluating the sufficiency of protected lands for maintaining wildlife population connectivity in the US northern Rocky Mountains. Divers Distrib 18(9):873-884

Cushman SA, Shirk A, Landguth EL (2012b) Separating the effects of habitat area, fragmentation and matrix resistance on genetic differentiation in complex landscapes. Landscape Ecol 27(3):369-380

Cushman SA, Lewis JS, Landguth EL (2013a) Evaluating the intersection of a regional wildlife connectivity network with highways. Mov Ecol 1(1):12

Cushman SA, McRae B, Adriaensen F, Beier P, Shirley M, Zeller K (2013b) Biological corridors and connectivity. In: Macdonald DW, Willis KJ (eds) Key topics in conservation biology 2. Wiley, Oxford, pp 384-404. https://doi.org/10. 1002/9781118520178.ch21

Cushman SA, Shirk AJ, Landguth EL (2013c) Landscape genetics and limiting factors. Conserv Genet 14(2):263-274 
Cushman SA, Lewis JS, Landguth EL (2014) Why did the bear cross the road? Comparing the performance of multiple resistance surfaces and connectivity modelling methods. Diversity 6(4):844-854

Cushman SA, Elliot NB, Macdonald DW, Loveridge AJ (2016) A multi-scale assessment of population connectivity in African lions (Panthera leo) in response to landscape change. Landscape Ecol 31(6):1337-1353

Cushman SA, Macdonald EA, Landguth EL, Malhi Y, Macdonald DW (2017) Multiple-scale prediction of forest loss risk across Borneo. Landscape Ecol 32(8):1581-1598

Fitzherbert EB, Struebig MJ, Morel A, Danielsen F, Brühl CA, Donald PF, Phalan B (2008) How will oil palm expansion affect biodiversity? Trends Ecol Evol 23(10):538-545

Gaveau DL, Sloan S, Molidena E, Yaen H, Sheil D, Abram NK, Ancrenaz M, Nasi R, Quinones M, Wielaard N, Meijaard E (2014) Four decades of forest persistence, clearance and logging on Borneo. PLoS ONE 9(7):e101654

Hearn AJ, Ross J, Pamin D, Bernard H, Hunter L, Macdonald DW (2013) Insights into the spatial and temporal ecology of the Sunda clouded leopard Neofelis diardi. Raffles Bull Zool 61(2):871-875

Hearn AJ, Ross J, Brodie J, Cheyne S, Haidir IA, Loken B, Mathai J, Wilting A and McCarthy J (2015) Neofelis dia$r d i$. The IUCN Red List of Threatened Species 2015

Hearn AJ, Ross J, Macdonald DW, Bolongon G, Cheyne SM, Mohamed A, Samejima H, Brodie JF, Giordano A, Alfred R, Boonratana R, Bernard H, Loken B, Augeri DM, Heydon M, Hon J, Mathai J, Marshall AJ, Pilgrim JD, Hall J, Breitenmoser-Würsten C, Kramer-Schadt S, Wilting A (2016) Predicted distribution of the Sunda Clouded leopard Neofelis diardi (Mammalia: Carnivora: Felidae) on Borneo. Raffles Bull Zool Suppl No. 33:165-172

Hearn AJ, Ross J, Bernard H, Bakar SA, Goossens B, Hunter LT, Macdonald DW (2017) Responses of Sunda clouded leopard Neofelis diardi population density to anthropogenic disturbance: refining estimates of its conservation status in Sabah. Oryx. https://doi.org/10.1017/ S0030605317001065

Hearn AJ, Cushman SA, Goossens B, Macdonald E, Ross J, Hunter L, Abram NK, Macdonald DW (2018) Evaluating scenarios of landscape change for Sunda clouded leopard connectivity in a human dominated landscape. Biol Conserv 222:232-240

Landguth EL, Cushman SA (2010) CDPOP: a spatially explicit cost distance population genetics program. Mol Ecol Resourc 10:156-161

Landguth EL, Cushman SA, Murphy MA, Luikart G (2010a) Relationships between migration rates and landscape resistance assessed using individual-based simulations. Mol Ecol Resourc 10(5):854-862

Landguth EL, Cushman SA, Schwartz MK, McKelvey KS, Murph M, Luikart G (2010b) Quantifying the lag time to detect barriers in landscape genetics. Mol Ecol 19(19):4179-4191

Landguth EL, Hand BK, Glassy J, Cushman SA, Sawaya MA (2012) UNICOR: a species connectivity and corridor network simulator. Ecography 35:9-14

Macdonald EA, Burnham D, Hinks AE, Dickman AJ, Malhi Y, Macdonald DW (2015) Conservation inequality and the charismatic cat: Felis felicis. Global Ecol Conserv 3:851-866

Macdonald EA, Cushman SA, Landguth EL, Hearn AJ, Malhi Y, Macdonald DW (2018) Implications of rapid forest loss on population size, connectivity and genetic diversity of clouded leopards in Borneo. PLoS ONE 13(9):e0196974. https://doi.org/10.1371/journal.pone.0196974

Malaysian Palm Oil Board (2016) Economics and industry development division. See http://bepi.mpob.gov.my/. Accessed May 2016

Mateo Sánchez MC, Cushman SA, Saura S (2014) Scale dependence in habitat selection: the case of the endangered brown bear (Ursus arctos) in the Cantabrian Range (NW Spain). Int J Geogr Inf Sci 28(8):1531-1546

Mateo-Sánchez MC, Balkenhol N, Cushman SA, Pérez T, Domínguez A, Saura S (2015) A comparative framework to infer landscape effects on population genetic structure: are habitat suitability models effective in explaining gene flow? Landscape Ecol 30(8):1405-1420

McGarigal K, Cushman SA (2002) Comparative evaluation of experimental approaches to the study of habitat fragmentation effects. Ecol Appl 12(2):335-345

McGarigal K, Cushman SA, Ene E (2012) FRAGSTATS v4: spatial pattern analysis program for categorical and continuous maps. Computer software program produced by the authors at the University of Massachusetts, Amherst. http:// www.umass.edu/landeco/research/fragstats/fragstats.html

McMorrow J, Talip MA (2001) Decline of forest area in Sabah, Malaysia: relationship to state policies, land code and land capability. Glob Environ Change 11(3):217-230

Meijaard E, Sheil D, Nasi R, Augeri D, Rosenbaum B, Iskandar D, Setyawati T, Lammertink M, Rachmatika I, Wong A, Soehartono T, Stanley S, O'Brien T (2005) Life after logging: reconciling wildlife conservation and production forestry in Indonesian Borneo. Centre for International Forestry Research, Bogor

Miettinen J, Shi C, Tan WJ, Liew SC (2012) 2010 land cover map of insular Southeast Asia in 250-m spatial resolution. Remote Sens Lett 3(1):11-20

Moqanaki EM, Cushman SA (2016) All roads lead to Iran: predicting landscape connectivity of the last stronghold for the critically endangered Asiatic cheetah. Anim Conserv 20(1):29-41

Reynolds G, Payne J, Sinun W, Mosigil G, Walsh RPD (2011) Changes in forest land use and management in Sabah, Malaysian Borneo, 1990-2010, with a focus on the Danum Valley region. Philos Trans R Soc B 366:3168-3176

Riordan P, Cushman SA, Mallon D, Shi K, Hughes J (2015) Predicting global population connectivity and targeting conservation action for snow leopard across its range. Ecography 39(5):419-426

Shirk, AJ, Wallin DO, Cushman SA, Rice CG, Warheit KI (2010) Inferring landscape effects on gene flow: a new model selection framework. Mol Ecol 19:3603-3619

Shirk AJ, Cushman SA, Landguth EL (2012) Simulating pattern-process relationships to validate landscape genetic models. International J Ecol. https://doi.org/10.1155/2012/ 539109

Shirk AJ, Raphael MG, Cushman SA (2014) Spatiotemporal variation in resource selection: insights from the American marten (Martes americana). Ecol Appl 24(6):1434-1444 
Shirk AJ, Schroeder MA, Robb LA, Cushman SA (2015) Empirical validation of landscape resistance models: insights from the Greater Sage-Grouse (Centrocercus urophasianus). Landscape Ecol 30(10):1837-1850

Shirk AJ, Landguth EL, Cushman SA (2018) A comparison of regression methods for model selection in individual-based landscape genetic analysis. Mol Ecol Resour 18(1):55-67

Short Bull RA, Cushman SA, Mace R, Chilton T, Kendall KC, Landguth EL, Schwartz MK, McKelvey K, Allendorf FW, Luikart G (2011) Why replication is important in landscape genetics: American black bear in the Rocky Mountains. Mol Ecol 20(6):1092-1107

Spear SF, Balkenhol N, Fortin MJ, McRae BH, Scribner KIM (2010) Use of resistance surfaces for landscape genetic studies: considerations for parameterization and analysis. Mol Ecol 19(17):3576-3591

Wasserman TN, Cushman SA, Schwartz MK, Wallin DO (2010) Spatial scaling and multi-model inference in landscape genetics: Martes americana in northern Idaho. Landscape Ecol 25(10):1601-1612

Wasserman TN, Cushman SA, Shirk AS, Landguth EL, Littell JS (2012) Simulating the effects of climate change on population connectivity of American marten (Martes americana) in the northern Rocky Mountains, USA. Landscape Ecol 27(2):211-225

Zeller KA, McGarigal K, Whiteley AR (2012) Estimating landscape resistance to movement: a review. Landscape Ecol 27(6):777-797

Zeller KA, Rabinowitz A, Salom-Perez R, Quigley H (2013) The Jaguar corridor initiative: a range-wide conservation strategy. In: Ruiz-Garcia M, Shostell JM (eds) Molecular population genetics, evolutionary biology and biological conservation of neotropical carnivores. Nova Science Publishers, New York, pp 629-658

Zeller KA, Vickers TW, Ernest HB, Boyce WM, Pollinger J, Ernest H (2017) Multi-level, multi-scale resource selection functions and resistance surfaces for conservation planning: Pumas as a case study. PLoS ONE 12:e0179570

Zeller KA, Jennings MK, Vickers TW, Ernest HB, Cushman SA, Boyce WM (2018) Are all data types and connectivity models created equal? Validating common connectivity approaches with dispersal data. Divers Distrib 24:868-879 